\title{
Formation of Advanced Glycosylation End Products and Oxidative Stress in Young Patients with Type 1 Diabetes
}

\author{
HIROKAZU TSUKAHARA, KYOUICHI SEKINE, MAYUMI UCHIYAMA, HISAKO KAWAKAMI, \\ IKUE HATA, YUKIKO TODOROKI, MASAHIRO HIRAOKA, MASAYUKI KAJI, TOHRU YORIFUJI, \\ TORU MOMOI, KAZUHIRO YOSHIHARA, MASATOSHI BEPPU, AND MITSUFUMI MAYUMI \\ Department of Pediatrics [H.T., I.H., Y.T., M.H., M.M.], Fukui Medical University, Fukui 910-1193, \\ Japan; Department of Research and Development [K.S., M.U., H.K.], Mitsubishi Kagaku Bio-Clinical \\ Laboratories, Tokyo 174-8555, Japan; Division of Endocrinology and Metabolism [M.K.], Shizuoka \\ Children's Hospital, Shizuoka 420-8660, Japan; Department of Pediatrics [T.Y.], Faculty of Medicine, \\ Kyoto University, Kyoto 606-8507, Japan; First Department of Pediatrics [T.M.], Japanese Red Cross \\ Society, Wakayama Medical Center, Wakayama 640-8558, Japan; and Laboratory of Public Health [K.Y., \\ M.B.], School of Pharmacy, Tokyo University of Pharmacy and Life Science, Tokyo 192-0392, Japan
}

\begin{abstract}
Increased production of advanced glycosylation end products (AGEs) and augmented oxidative stress may contribute to vascular complications in diabetes. Little is known about the formation and accumulation of AGEs in young patients with type 1 diabetes. The aim of the present study was to investigate whether AGE production and oxidative stress are augmented in young patients with type 1 diabetes at early clinical stages of the disease. Urine samples of 38 patients with type 1 diabetes [mean age ( $\pm \mathrm{SD}), 12.8 \pm 4.5 \mathrm{y}$; diabetes duration, $5.7 \pm 4.3 \mathrm{y} ; \mathrm{HbA}_{1 \mathrm{c}}$, $8.0 \pm 1.6 \%$; urinary albumin excretion, $12.6 \pm 14.4 \mathrm{mg} / \mathrm{g}$ creatinine $(\mathrm{Cr})]$ and those of 60 age-matched healthy control subjects were assayed for AGEs, pentosidine and pyrraline, and markers of oxidative stress, 8-hydroxy-2'-deoxyguanosine (8$\mathrm{OHdG}$ ) and acrolein-lysine. Of these four markers, urinary concentrations of pentosidine, $8-\mathrm{OHdG}$, and acrolein-lysine were significantly higher in the patients with diabetes than in the healthy control subjects. For the patient group, pentosidine correlated significantly with $8-\mathrm{OHdG}$ and acrolein-lysine, and pyrraline correlated significantly with acrolein-lysine. Urinary pen-
\end{abstract}

\section{ABSTRACT}

tosidine, $8-\mathrm{OHdG}$, and acrolein-lysine but not pyrraline correlated significantly with urinary albumin excretion. Patients with microalbuminuria ( $\geq 15 \mathrm{mg} / \mathrm{g} \mathrm{Cr}$ ) showed significantly higher levels of all four markers than did normoalbuminuric patients and control subjects. The present study indicates that accumulation of AGEs, whose formation is closely linked to oxidative stress, and resultant endothelial dysfunction may start early in the course of type 1 diabetes. This means that the risk of vascular complications may be present at an early age and that the best possible glycemic control should be emphasized from the diagnosis of diabetes. (Pediatr Res 54: 419-424, 2003)
Abbreviations
AGE, advanced glycosylation end product
RAGE, advanced glycosylation end product-specific receptor
8-OHdG, 8-hydroxy-2'-deoxyguanosine
Cr, creatinine
ROI, reactive oxygen intermediate

As first described by Maillard, glucose and reducing sugars react nonenzymatically with protein amino groups to form reversible Schiff base adducts, which, upon molecular rearrangement, convert in vivo into the more stable Amadori products such as $\mathrm{HbA}_{1 \mathrm{c}}(1,2)$. A small proportion of Amadori products are then irreversibly transformed, over several weeks

Received October 2, 2002; accepted March 11, 2003.

Correspondence: Hirokazu Tsukahara, M.D., Ph.D., Department of Pediatrics, Fukui Medical University, Fukui 910-1193, Japan; e-mail: htsuka@fmsrsa.fukui-med.ac.jp

Supported in part by a research grant from the Ministry of Education, Science and Culture of Japan.

DOI: 10.1203/01.PDR.0000076662.72100.74 to months, into advanced glycosylation end products (AGEs). The latter process is slow and affects mainly proteins with a slow turnover, such as matrix tissue proteins.

Generation of AGEs was first described as an epiphenomenon of aging. AGE contents slowly increase with age in a variety of collagenous structures, such as vascular wall collagen and basement membranes. Subsequent studies showed accumulation of AGEs during the progression of diabetes (1-3), whereas others identified AGEs in the blood and tissues of patients with chronic renal failure $(4,5)$. In the latter group, AGE generation was not linked to the glycemic status. AGE formation is accompanied by a cross-linking of proteins caus- 
ing alterations of structural and functional properties of macromolecules. Furthermore, AGEs have been shown to display diverse biologic activities, such as increase in endothelial permeability; binding to AGE-specific receptors (RAGEs) on macrophages, endothelial cells, vascular smooth muscle cells, and glomerular mesangial cells; activation of these cells with secretion of cytokines and growth factors, which in turn accelerate chronic inflammation; quenching of the vasodilator and antiproliferative effects of nitric oxide; enhancing oxidative stress; and oxidation of LDL $(1-3,5)$.

It has been hypothesized that AGEs play a causal role in the development of a variety of diabetic complications $(1-3,5)$. AGEs accumulate in plasma and tissue proteins of patients with diabetes(6-8). Their accumulation correlates with the severity of diabetic complications. Miyata and colleagues $(3,9)$ recently demonstrated that carboxymethyl-lysine and pentosidine, which are AGE compounds, accumulate in expanded mesangial matrix and nodular lesions in diabetic nephropathy, in co-localization with lipid peroxidation end products such as malondialdehyde-lysine, 4-hydroxynonenal-protein adduct, and acrolein-protein adduct. However, pyrraline, another AGE structure whose deposition is independent of oxidative stress, was not found within diabetic glomeruli. Animal studies suggest that inhibitors of advanced glycosylation such as aminoguanidine and OPB-9195 prevent diabetic complications and thus support the above hypothesis $(10,11)$.

Because measurement of AGEs in tissue specimens is not useful clinically, analyses of blood and urine samples have been pursued. Recently, we developed a rapid and accurate method for the determination of urinary and serum pentosidine (12) and urinary pyrraline (13) by HPLC with fluorometric detection. Using this method, we found that urinary and serum concentrations of pentosidine in control subjects (aged 22 to $70 \mathrm{y}$ ) gradually increased with age, whereas urinary pyrraline did not increase with aging (from 20 to $77 \mathrm{y}$ ), and that elder patients with cerebral infarction showed higher levels of pentosidine compared with their control subjects. In contrast to numerous investigations in adults, little is known about the formation and accumulation of AGEs in young patients. Furthermore, urinary levels of AGEs have not been previously examined in young patients with type 1 diabetes and even in healthy children and adolescents.

The objective of the present work was to study markers of reactive AGE formation, urinary pentosidine and pyrraline, as well as markers of oxidative stress, 8-hydroxy-2'-deoxyguanosine $(8-\mathrm{OHdG})(14)$ and acrolein-lysine $(15,16)$, in a group of young patients with type 1 diabetes with normal renal function and to compare the findings with those of the control group of similar age. In the present study, we provide evidence for the first time of both increased AGE formation and augmented oxidative stress in young patients with type 1 diabetes.

\section{METHODS}

Patients and control subjects. We examined 38 young Japanese patients with type 1 diabetes (17 male and 21 female). The mean age $( \pm \mathrm{SD})$ was $12.8 \pm 4.5 \mathrm{y}$ (range, $3.8-21.3 \mathrm{y}$ ), diabetes duration was $5.7 \pm 4.3$ y $(0.3-16.8 \mathrm{y}), \mathrm{HbA}_{1 \mathrm{c}}$ was 8.0 $\pm 1.6 \%(4.4-12.6 \%)$, and body mass index $\left(\mathrm{kg} / \mathrm{m}^{2}\right)$ was 18.9 $\pm 2.3(14.8-25.6)$. All patients were on a diabetes diet and were treated with insulin $\left(0.98 \pm 0.40 \mathrm{IU} \cdot \mathrm{kg}^{-1} \cdot \mathrm{d}^{-1}\right.$; range, $\left.0.23-2.05 \mathrm{IU} \cdot \mathrm{kg}^{-1} \cdot \mathrm{d}^{-1}\right)$. They were not taking other medications. All patients were normotensive and had normal (defined as $<1.2 \mathrm{mg} / \mathrm{dL}$ ) serum creatinine $(\mathrm{Cr})$ concentrations $(0.53 \pm 0.19 \mathrm{mg} / \mathrm{dL}$; range, $0.20-1.09 \mathrm{mg} / \mathrm{dL})$. Their urinary albumin excretion was $12.6 \pm 14.4 \mathrm{mg} / \mathrm{g} \mathrm{Cr}(1.4-76.2 \mathrm{mg} / \mathrm{g}$ $\mathrm{Cr}$ ), and $11 \mathrm{had}$ microalbuminuria (defined as $\geq 15 \mathrm{mg} / \mathrm{g} \mathrm{Cr}$ ). None had any clinical evidence of retinopathy or neuropathy. We also recruited 60 healthy Japanese subjects (28 male and 32 female) as the control group, with a broad age range (11.4 \pm $4.5 \mathrm{y}$; range, 4.2-21.0 y) to encompass the ages of the patients with diabetes. None of the control subjects was taking any medication.

All subjects were nonsmokers. None of them had any acute illness or chronic condition at the time of study. The nature and purpose of the study were explained to the subjects and/or their parents, and informed consent was obtained from them before enrollment. Approval of the project was obtained from the local medical ethics committee.

Sample collection. Early-morning void urine samples were obtained from each subject. The samples were centrifuged, and the supernatants were stored at $-20^{\circ} \mathrm{C}$ until analysis. All analyses were performed in duplicate, and the examiner was blinded to the clinical and laboratory results.

Determination of urinary pentosidine. The washing solution was a mixture of $n$-butanol-acetic acid:hydrochloric acid $(8: 1: 1, \mathrm{vol} / \mathrm{vol})$. CF-1 slurry was prepared by making a $5 \%$ (wt/vol) suspension of CF-1 cellulose powder in the washing solvent. The pretreatment column was prepared by adding 8 $\mathrm{mL}$ of CF-1 slurry to a Poly-Prep chromatography column $(0.8$ $\mathrm{mm} \times 40 \mathrm{~mm}$, internal diameter (i.d.); Bio-Rad, Hercules, CA, U.S.A.). A total of $250 \mu \mathrm{l}$ of urine was hydrolyzed with an equal volume of concentrated hydrochloric acid at $108^{\circ} \mathrm{C}$ for $18 \mathrm{~h}$. The cooled hydrolysate $(250 \mu \mathrm{L})$ was mixed with $250 \mu \mathrm{L}$ of CF-1 slurry, $250 \mu \mathrm{L}$ of acetic acid, and $2 \mathrm{~mL}$ of $n$-butanol, then loaded to the pretreatment column. After the column was washed with $35 \mathrm{~mL}$ of the washing solvent, pentosidine was eluted from the column with $9 \mathrm{~mL}$ of $50 \mathrm{mM}$ of hydrochloric acid and blown up to dryness under $\mathrm{N}_{2}$ gas flow. The dry residue was then dissolved in $250 \mu \mathrm{L}$ of $1 \% n$-heptafluorobutyric acid (vol/vol), and an aliquot $(10 \mu \mathrm{L})$ of each sample was applied to analytical HPLC. The HPLC eluent was 7\% acetonitrile ( $\mathrm{vol} / \mathrm{vol})$ containing $0.1 \% n$-heptafluorobutyric acid. The HPLC system was equipped with an L-6200 intelligent pump (Hitachi, Ibaragi, Japan), an F-1050 fluorescence detector set at excitation and emission wavelengths of $335 \mathrm{~nm}$ and $385 \mathrm{~nm}$, respectively (Hitachi), and Symmetry RP18 column $(3.5 \mu \mathrm{m}, 4.6 \mathrm{~mm} \times 150 \mathrm{~mm}$, i.d.; Waters, Milford, MA, U.S.A.). The flow rate was maintained at $0.8 \mathrm{~mL} / \mathrm{min}$, and the column was kept at $30^{\circ} \mathrm{C}$. Standard pentosidine was synthesized and purified, as described in detail by our laboratories previously (12). Values obtained for healthy adults $(n=64)$ are $28.2 \pm 12.0 \mathrm{pmol} / \mathrm{mg} \mathrm{Cr}$.

Determination of urinary pyrraline. The solid-phase extraction cartridge, Oasis HLB (3 mL; Waters), was used for pretreatment of urine samples. The cartridge was precondi- 
tioned with $1 \mathrm{~mL}$ of methanol and equilibrated with $1 \mathrm{~mL}$ of distilled water before loading the sample. A total of $500 \mu \mathrm{l}$ of urine sample was applied to the cartridge, followed by washing the cartridge with $1 \mathrm{~mL}$ of $0.1 \%$ acetic acid (vol/vol). Pyrraline was eluted from the cartridge with $3 \mathrm{~mL}$ of $60 \%$ acetonitrile, and the eluent was blown up to dryness under $\mathrm{N}_{2}$ gas flow. The dried residue was then dissolved in $500 \mu \mathrm{L}$ of $0.1 \%$ trifluoroacetic acid (vol/vol), and an aliquot $(20 \mu \mathrm{L})$ of each sample was applied to the analytical HPLC system. The HPLC eluent was $7 \%$ acetonitrile (vol $/ \mathrm{vol}$ ) containing $0.1 \%$ trifluoroacetic acid (vol/vol). The HPLC system was equipped with an L-7100 intelligent pump, an L-7400 UV detector set at $298 \mathrm{~nm}$, and Capcellpak UG120 column $(3 \mu \mathrm{m}, 4.6 \mathrm{~mm} \times 150 \mathrm{~mm}$, i.d.; Shiseido, Tokyo, Japan). The flow rate was maintained at 0.8 $\mathrm{mL} / \mathrm{min}$, and the column was kept at $35^{\circ} \mathrm{C}$. Standard pyrraline was synthesized and purified (13). Values obtained for healthy adults $(n=27)$ are $25.3 \pm 30.0 \mathrm{nmol} / \mathrm{mg} \mathrm{Cr}$.

Determination of urinary markers of oxidative stress. Currently, 8-OHdG is one of the most popular markers for oxidative DNA damage and oxidative stress in vivo (14). Acrolein $\left(\mathrm{CH}_{2}=\mathrm{CH}-\mathrm{CHO}\right)$ is one of the major lipid peroxidation products with cytotoxic and mutagenic activities $(15,16)$. Among $\alpha, \beta$-unsaturated aldehydes, acrolein is by far the strongest electrophile and reacts with nucleophiles, such as the sulfhydryl group of cysteine, imidazole group of histidine, and amino group of lysine. Acrolein-lysine adduct can be used as a reliable index of lipid peroxidation in vivo.

The concentrations of $8-\mathrm{OHdG}$ and acrolein-lysine were determined using competitive ELISA kits (8-OHdG Check, Institute for the Control of Aging, Shizuoka, Japan (17); ACR-Lysine Adduct ELISA, NOF Corporation, Tokyo (18), respectively). The assay variances of all methods described above were $<10 \%$.

Measurement of urinary $\boldsymbol{C r}$. All urinary markers were expressed relative to urinary $\mathrm{Cr}$ concentration, which was measured enzymatically by using the Creatinine HR-II Test kit (Wako Pure Chemicals, Osaka, Japan).

Statistical analysis. Data are presented as mean \pm SD and range. Comparisons between groups were analyzed by twotailed $t$ test. Correlations between variables were assessed by linear regression. $P<0.05$ was considered statistically significant.

\section{RESULTS}

Table 1 shows the concentrations of pentosidine, pyrraline, 8 -OHdG, and acrolein-lysine adduct in urinary samples of 60 control subjects and 38 patients with type 1 diabetes. Of these four markers, urinary levels of pentosidine, $8-\mathrm{OHdG}$, and acrolein-lysine were significantly higher in patients with type 1 diabetes than in control subjects. For the diabetic group, urinary pentosidine levels correlated significantly with those of urinary pyrraline. Furthermore, pentosidine levels correlated significantly with those of 8-OHdG and acrolein-lysine, and pyrraline levels correlated significantly with those of acroleinlysine (Fig. 1). Of these four markers, urinary levels of pentosidine $(r=0.32, p<0.05), 8$-OHdG $(r=0.57, p<0.001)$, and acrolein-lysine $(r=0.38, p<0.05)$ but not pyrraline $(r=$ 0.11 ) correlated significantly with urinary albumin creatinine ratio. Only urinary levels of $8-\mathrm{OHdG}$ significantly correlated with $\mathrm{HbA}_{1 \mathrm{c}}$ values $(r=0.41, p<0.05)$. Urinary albumin creatinine ratio correlated with $\mathrm{HbA}_{1 \mathrm{c}}(r=0.44, p<0.01)$.

When the patients with diabetes were divided into two subgroups according to the presence of microalbuminuria $(\geq 15 \mathrm{mg} / \mathrm{g} \mathrm{Cr}$ ), significantly higher urinary concentrations of pentosidine, pyrraline, 8-OHdG, and acrolein-lysine were noted in patients with microalbuminuria $(n=11)$ than in normoalbuminuric patients $(n=27)$ and the control subjects (Table 1). Microalbuminuric patients also had significantly high $\mathrm{HbA}_{1 \mathrm{c}}$ values compared with normoalbuminuric patients $(8.9 \pm 1.7 \%$ versus $7.6 \pm 1.5 \% ; p<0.05)$. There was no significant difference in age and duration of diabetes between these two subgroups of patients $(11.8 \pm 6.1$ versus $13.3 \pm$ $3.6 \mathrm{y}$ and $5.0 \pm 3.7$ versus $6.0 \pm 4.6 \mathrm{y}$, respectively).

\section{DISCUSSION}

With the rapid development of therapy for diabetes, the mortality rate associated with acute complications has decreased but that associated with chronic complications of diabetes has increased (3). Diabetic nephropathy is one of the major chronic complications of both type 1 and type 2 diabetes and also an important cause of increased morbidity and mortality among these patients. Therefore, elucidation of the molecular pathogenesis of diabetic nephropathy is critical for the

Table 1. Urinary markers of advanced glycosylation and oxidative stress in control subjects and patients with type 1 diabetes

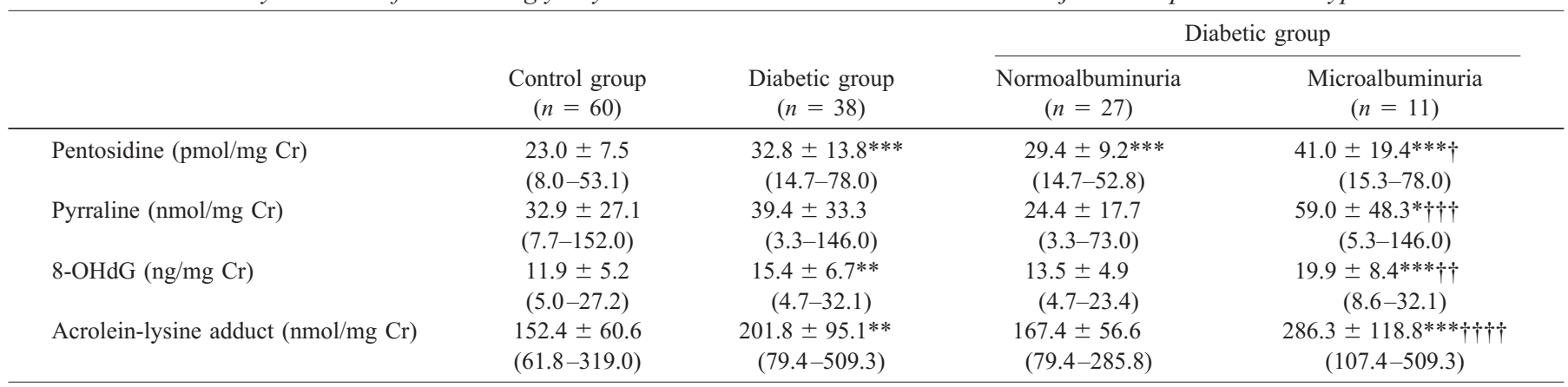

Data are presented as mean $\pm \mathrm{SD}$ and range. $* P<0.05$, ** $P<0.005, * * * P<0.001$ vs control; $\dagger P<0.05, \dagger \dagger P<0.01, \dagger \dagger \dagger P<0.005, \dagger \dagger \dagger P<0.001$ vs Normoalbuminuria. 

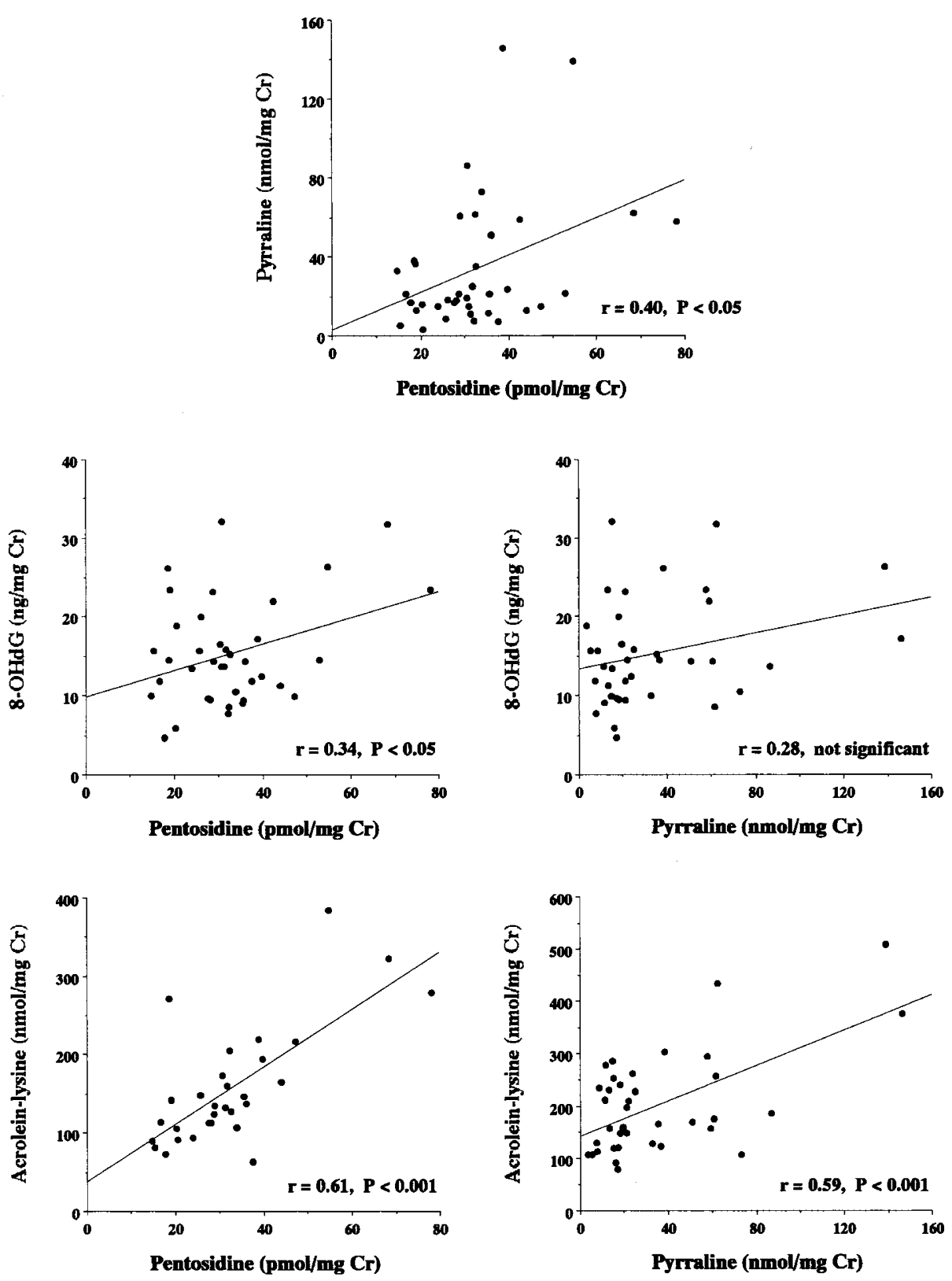

Figure 1. Relationships between urinary concentrations of pentosidine, pyrraline, 8-OHdG, and acrolein-lysine adduct in patients with type 1 diabetes.

design of new and effective management protocols to prevent the onset of or to halt the development of diabetic nephropathy.

Although the Diabetes Control and Complications Trial has identified sustained hyperglycemia, as measured by $\mathrm{HbA}_{1 \mathrm{c}}$, as a risk factor for the development of diabetic complications (19), there is no consensus regarding the pathogenic link between hyperglycemia and complications. There are a number of equally tenable hypotheses on the origin of complications, including but not limited to the Maillard or AGE hypothesis, the aldose reductase hypothesis, oxidative stress, reductive stress, altered lipoprotein metabolism, increased protein kinase $\mathrm{C}$ activity, and altered growth factor or cytokine activities (20). These various hypotheses seem to overlap and intersect with one another.

The objective of our work was to study one of the above hypotheses, the AGE hypothesis, in young patients with type 1 diabetes and normal renal function. Because the AGE hypothesis and oxidative stress are inextricably intertwined, we also examined the status of oxidative stress in these patients. For these purposes, we determined the urinary concentrations of pentosidine and pyrraline, representing AGEs, as well as those of 8-OHdG and acrolein-lysine adduct, representing oxidative cellular damage. Measurement of urinary specific markers enables repeated monitoring of AGE formation and oxidative stress, which is otherwise not possible with invasive tests.

In the present study, we found significantly higher urinary concentrations of pentosidine in young patients with type 1 diabetes as compared with age-matched healthy control subjects, whereas pyrraline levels were not increased. Our results support the findings of the recent studies of Berg et al. $(21,22)$, Chiarelli et al. (23, 24), and Misselwitz et al. (25). These investigators found that serum concentrations of AGEs, includ- 
ing carboxymethyl-lysine and pentosidine, were significantly increased in young patients with type 1 diabetes compared with control subjects. Berg et al. (21) performed serial renal biopsies in 10- to 30-year-old patients who had type 1 diabetes and microalbuminuria with normal renal function. They found a significant correlation between $\mathrm{AGE}$ levels but not $\mathrm{HbA}_{1 \mathrm{c}}$ at the start of the study and the progression of early morphologic renal damage at the follow-up biopsy 26 to 34 mo later. Chiarelli et al. (24) found a close correlation between serum AGE concentrations and the severity of diabetic retinopathy and microalbuminuria. A highly significant relationship between glycemic control (based on $\mathrm{HbA}_{1 \mathrm{c}}$ ) and collagen-linked AGEs was also demonstrated in skin biopsy specimens from adults with type 1 diabetes (26). These findings support the view that serum levels of AGEs are equivalent to AGEs in the tissues and organs. Previously, we found a close correlation between serum and urinary concentrations of pentosidine not only in 26 subjects with normal renal function (12) but also in 44 patients with impaired renal function (unpublished observations). These results indicate that pentosidine in the circulation is duly excreted into the urine according to its serum concentration. Therefore, we assume that the increased excretion of pentosidine observed in our patients with diabetes reflects a greater synthesis and accumulation in the serum, tissues, and organs.

We also found significantly higher concentrations of urinary 8 -OHdG and acrolein-lysine in our patients with diabetes compared with the healthy control subjects. The results indicate the presence of greater oxidative damage to DNA and lipid peroxidation in young patients with type 1 diabetes. The metabolic disturbances in diabetes may favor generation of excess reactive oxygen intermediates (ROIs), and this might be associated with reduced activity of antioxidants (20). Evidence indicating that systemic oxidative stress occurs in young patients with type 1 diabetes and may play an important role in the pathogenesis of endothelial perturbation and diabetic complications has accumulated (27-29). Specifically, high levels of malondialdehyde and protein carbonyl groups and low levels of thiols in plasma, low erythrocyte glutathione levels, and glutathione peroxidase activities, as well as high levels of E-selectin and intercellular cell adhesion molecule in plasma, have been reported. We now extend these observations to urinary specific markers of oxidative DNA damage (i.e. 8-OHdG) and lipid peroxidation (i.e. acrolein-lysine adduct) and provide additional evidence that ROIs may exert their cytotoxic effects at early clinical stages of type 1 diabetes.

In our diabetic group, both AGE products significantly correlated with each other, and there were significant correlations between pentosidine and either 8-OHdG or acroleinlysine and between pyrraline and acrolein-lysine. The present study is the first demonstration of a possible link between reactive AGE formation and oxidative stress in young patients with diabetes. AGEs exert their cellular effects on several cell types, including glomerular mesangial cells, by interacting with specific receptor or RAGE (1). A key consequence of the interaction of AGEs with RAGEs is the generation of ROIs. In vitro and/or in vivo AGE-RAGE interaction results in the generation of ROIs, activation of NADPH oxidase, stimulation of Ras/Raf/MEK/ERK1/2, enhancement of nuclear translocation of nuclear factor-kappa B and activator protein-1, induction of heme oxygenase-1, and increased endothelial permeability and expression of vascular cell adhesion molecules (30-34). These studies revealed that generation of ROIs and enhanced oxidative stress is a potent factor capable of initiating signal transduction and altered gene expression, because the AGE-RAGE-mediated effects were inhibited in the presence of antioxidants such as $N$-acetylcysteine, probucol, vitamin E, or nitecapone. However, ROIs are produced in the Maillard reaction and also help to form AGEs $(3,5)$. Support for the causal role of high oxidative stress in AGE formation may be the correlation present in the serum of uremic patients between pentosidine and oxidative markers such as advanced oxidation protein products (35) and dehydroascorbate (36). Furthermore, the co-localization of AGEs with markers of lipid peroxidation in vascular and renal tissues suggests that both glycosylation and oxidation reactions contribute to pathologic lesions in diabetic atherosclerosis and nephropathy $(9,37)$. Indeed, AGE formation pathways consist of two types; one requires oxidative conditions, and the other requires nonoxidative conditions $(3,5,20)$. Pentosidine is produced by the combined processes of glycosylation and oxidation (thereby termed glycoxidation) (38), and pyrraline is derived from nonoxidative chemistry (39). A recent study by Rodriguez-Garcia et al. (40) showed not only that hyperglycemia is a factor in pentosidine formation but also that oxidative reactions cause accumulation of pentosidine in rheumatoid arthritis with normoglycemia and normal renal function. Therefore, our findings of increased concentrations of pentosidine, $8-\mathrm{OHdG}$, and acrolein-lysine and their close interrelationship, together with seemingly normal pyrraline concentrations, in patients with diabetes are interpreted as evidence that pentosidine levels are partly determined by the severity of prevailing oxidative stress in these patients.

Another important demonstration of the present study was that in our patients with diabetes and normal renal function, microalbuminuria was closely linked with higher urinary concentrations of pentosidine, pyrraline, $8-\mathrm{OHdG}$, and acroleinlysine adduct, in addition to the poorer quality of glycemic control (expressed by higher $\mathrm{HbA}_{1 \mathrm{c}}$ values). Of interest are data showing a significant increase of urinary pyrraline in the patients with diabetes and microalbuminuria relative to the healthy control subjects. Because albuminuria may represent disruption of the endothelial barrier in the kidney, our findings suggest that both AGE formation and enhanced oxidative stress are involved in the progression to the earliest detectable clinical stages of microvasculopathy in type 1 diabetes. We did not see any correlation between urinary concentrations of both AGEs and $\mathrm{HbA}_{1 \mathrm{c}}$ levels. This finding is consistent with the results of Berg et al. (22) and Misselwitz et al. (25) but not with those of Chiarelli et al. $(23,24)$. The difference in the results may be explained by the fact that glycosylated $\mathrm{HbA}_{1 \mathrm{c}}$ is an indicator of the glycemic status of the preceding several weeks, whereas AGEs reflect a process over a longer period.

Children and adolescents with type 1 diabetes were previously considered to be protected from vascular diseases, which become clinically apparent only by early adulthood. However, 
this concept has been challenged recently. There is an increasing body of evidence supporting the hypothesis that endothelial dysfunction, a forerunner of diabetic vasculopathy, is present early in the course of diabetes $(20,28,41,42)$. The present study shows that accumulation of AGEs, whose formation is closely linked to oxidative stress, and resultant endothelial dysfunction may start early in the course of type 1 diabetes and supports the contention that good glycemic control should be emphasized from the diagnosis of diabetes to prevent the development or to slow the progression of vascular complications.

\section{REFERENCES}

1. Vlassara H, Bucala R, Striker L 1994 Pathogenic effects of advanced glycosylation: biochemical, biologic, and clinical implications for diabetes and aging. Lab Invest 70:138-151

2. Bucala R, Vlassara H 1995 Advanced glycosylation end products in diabetic renal and vascular disease. Am J Kidney Dis 26:875-888

3. Suzuki D, Miyata T 1999 Carbonyl stress in the pathogenesis of diabetic nephropathy. Intern Med 38:309-314

4. Makita Z, Bucala R, Rayfield EJ, Friedman EA, Kaufman AM, Korbet SM, Barth RH, Winston JA, Fuh H, Manogue KR, Cerami A, Vlassara H 1994 Reactive glycosylation endproducts in diabetic uraemia and treatment of renal failure. Lancet 343:15191522

5. Miyata T, Kurokawa K, van Ypersele de Strihou C 2000 Advanced glycation and lipoxidation end products: role of reactive carbonyl compounds generated during carbohydrate and lipid metabolism. J Am Soc Nephrol 11:1744-1752

6. Sell DR, Lapolla A, Odetti P, Fogarty J, Monnier VM 1992 Pentosidine formation in skin correlates with severity of complications in individuals with long-standing IDDM. Diabetes 41:1286-1292

7. McCance DR, Dyer DG, Dunn JA, Bailie KE, Thorpe SR, Baynes JW, Lyons TJ 1993 Maillard reaction products and their relation to complications in insulin-dependent diabetes mellitus. J Clin Invest 91:2470-2478

8. Sugiyama S, Miyata T, Ueda Y, Tanaka H, Maeda K, Kawashima S, van Ypersele de Strihou C, Kurokawa K 1998 Plasma levels of pentosidine in diabetic patients: an advanced glycation end product. J Am Soc Nephrol 9:1681-1688

9. Horie K, Miyata T, Maeda K, Miyata S, Sugiyama S, Sakai H, van Ypersele de Strihou C, Monnier VM, Witztum JL, Kurokawa K 1997 Immunohistochemical colocalization of glycoxidation products and lipid peroxidation products in diabetic renal glomerular lesions: implication for glycoxidative stress in the pathogenesis of diabetic nephropathy. J Clin Invest 100:2995-3004

10. Vlassara H, Striker LJ, Teichberg S, Fuh H, Li YM, Steffes M 1994 Advanced glycation end products induce glomerular sclerosis and albuminuria in normal rats. Proc Natl Acad Sci U S A 91:11704-11708

11. Nakamura S, Makita Z, Ishikawa S, Yasumura K, Fujii W, Yanagisawa K, Kawata T, Koike T 1997 Progression of nephropathy in spontaneous diabetic rats is prevented by OPB-9195, a novel inhibitor of advanced glycation. Diabetes 46:895-899

12. Yoshihara K, Nakamura K, Kanai M, Nagayama Y, Takahashi S, Saito N, Nagata M 1998 Determination of urinary and serum pentosidine and its application to elder patients. Biol Pharm Bull 21:1005-1008

13. Yoshihara K, Kiyonami R, Shimizu Y, Beppu M 2001 Determination of urinary pyrraline by solid-phase extraction and high performance liquid chromatography. Biol Pharm Bull 24:863-866

14. Toyokuni S 1999 Reactive oxygen species-induced molecular damage and its application in pathology. Pathol Int 49:91-102

15. Uchida K, Kanematsu M, Sakai K, Matsuda T, Hattori N, Mizuno Y, Suzuki D, Miyata T, Noguchi N, Niki E, Osawa T 1998 Protein-bound acrolein: potential markers for oxidative stress. Proc Natl Acad Sci U S A 95:4882-4887

16. Uchida K 1999 Current status of acrolein as a lipid peroxidation product. Trends Cardiovasc Med 9:109-113

17. Omata N, Tsukahara H, Ito S, Ohshima Y, Yasutomi M, Yamada A, Jiang M, Hiraoka M, Nambu M, Deguchi Y, Mayumi M 2001 Increased oxidative stress in childhood atopic dermatitis. Life Sci 69:223-228

18. Satoh K, Yamada S, Koike Y, Igarashi Y, Toyokuni S, Kumano T, Takahata T, Hayakari M, Tsuchida S, Uchida K 1999 A 1-hour enzyme-linked immunosorben assay for quantitation of acrolein- and hydroxynonenal-modified proteins by epitopebound casein matrix method. Anal Biochem 270:323-328

19. The Diabetes Control and Complications Trial Research Group 1993 The effect of intensive treatment of diabetes on the development and progression of long-term complications of insulin-dependent diabetes mellitus. N Engl J Med 329:977-986
20. Baynes JW, Thorpe SR 1999 Role of oxidative stress in diabetic complications: a new perspective on an old paradigm. Diabetes 48:1-99

21. Berg TJ, Bangstad HJ, Torjesen PA, Osterby R, Bucala R, Hanssen KF 1997 Advanced glycation end products in serum predict changes in the kidney morphology of patients with insulin-dependent diabetes mellitus. Metabolism 46:661-665

22. Berg TJ, Clausen JT, Torjesen PA, Dahl-Jorgensen K, Bangstad HJ, Hanssen KF 1998 The advanced glycation end product $\mathrm{N}^{\epsilon}$-(carboxymethyl)lysine is increased in serum from children and adolescents with type 1 diabetes. Diabetes Care 21:19972002

23. Chiarelli F, de Martino M, Mezzetti A, Catino M, Morgese G, Cuccurullo F, Verrotti A 1999 Advanced glycation end products in children and adolescents with diabetes: relation to glycemic control and early microvascular complications. J Pediatr 134:486-491

24. Chiarelli F, Catino M, Tumini S, Cipollone F, Mezzetti A, Vanelli M, Verrotti A 2000 Advanced glycation end products in adolescents and young adults with diabetic angiopathy. Pediatr Nephrol 14:841-846

25. Misselwitz J, Franke S, Kauf E, John U, Stein G 2002 Advanced glycation end products in children with chronic renal failure and type 1 diabetes. Pediatr Nephrol $17: 316-321$

26. Beisswenger PJ, Moore LL, Curphey TJ 1993 Relationship between glycemic control and collagen-linked advanced glycosylation end products in type 1 diabetes. Diabetes Care 16:689-694

27. Dominguez C, Ruiz E, Gussinye M, Carrascosa A 1998 Oxidative stress at onset and in early stages of type 1 diabetes in children and adolescents. Diabetes Care 21:1736-1742

28. Elhadd TA, Kennedy G, Hill A, McLaren M, Newton RW, Greene SA, Belch JJF 1999 Abnormal markers of endothelial cell activation and oxidative stress in children, adolescents and young adults with type 1 diabetes with no clinical vascular disease. Diabetes Metab Res Rev 15:405-411

29. Telci A, Cakatay U, Salman S, Satman I, Sivas A 2000 Oxidative protein damage in early stage type 1 diabetic patients. Diabetes Res Clin Pract 50:213-223

30. Yan SD, Schmidt AM, Anderson GM, Zhang J, Brett J, Zou YS, Pinsky D, Stern D 1994 Enhanced cellular oxidant stress by the interaction of advanced glycation end products with their receptors/binding proteins. J Biol Chem 269:9889-9897

31. Wautier JL, Wautier MP, Schmidt AM, Anderson GM, Hori O, Zoukourian C, Capron L, Chappey O, Yan SD, Brett J, Guillausseau PJ, Stern D 1999 Advanced glycation end products (AGEs) on the surface of diabetic erythrocytes bind to the vessel wall via a specific receptor inducing oxidant stress in the vasculature: a link between surface-associated AGEs and diabetic complications. Proc Natl Acad Sci U S A 91:7742-7746

32. Lander HM, Tauras JM, Ogiste JS, Hori O, Moss RA, Schmidt AM 1997 Activation of the receptor for advanced glycation end products triggers a $\mathrm{p} 21^{\text {ras }}$-dependent mitogen-activated protein kinase pathway regulated by oxidant stress. J Biol Chem 272:17810-17814

33. Urata Y, Yamaguchi M, Higashiyama Y, Ihara Y, Goto S, Kuwano M, Horiuchi S, Sumikawa K, Kondo T 2002 Reactive oxygen species accelerate production of vascular endothelial growth factor by advanced glycation end products in RAW264.7 mouse macrophages. Free Radic Biol Med 32:688-701

34. Lal MA, Brismar H, Eklof AC, Aperia A 2002 Role of oxidative stress in advanced glycation end product-induced mesangial cell activation. Kidney Int 61:2006-2014

35. Witko-Sarsat V, Friedlander M, Capeillere-Blandin C, Nguyen-Khoa T, Nguyen AT, Zingraff J, Jungers P, Descamps-Latscha B 1996 Advanced oxidation protein products as a novel marker of oxidative stress in uremia. Kidney Int 49:1304-1313

36. Miyata T, Wada Y, Cai Z, Iida Y, Horie K, Yasuda Y, Maeda K, Kurokawa K, van Ypersele de Strihou C 1997 Implication of an increased oxidative stress in the formation of advanced glycation end products in patients with end-stage renal failure. Kidney Int 51:1170-1181

37. Miyata T, Inagi R, Asahi K, Yamada Y, Horie K, Sakai H, Uchida K, Kurokawa K 1998 Generation of protein carbonyls by glycoxidation and lipoxidation reactions with autoxidation products of ascorbic acid and polyunsaturated fatty acids. FEBS Lett 437:24-28

38. Dyer DG, Blackledge JA, Thorpe SR, Baynes JW 1991 Formation of pentosidine during nonenzymatic browning of proteins by glucose: identification of glucose and other carbohydrates as possible precursors of pentosidine in vivo. J Biol Chem 266:11654-11660

39. Hayase F, Nagaraj RH, Miyata S, Njoroge FG, Monnier VM 1989 Aging of proteins: immunological detection of a glucose-derived pyrrole formed during Maillard reaction in vivo. J Biol Chem 264:3758-3764

40. Rodriguez-Garcia J, Requena JR, Rodriguez-Segade S 1998 Increased concentrations of serum pentosidine in rheumatoid arthritis. Clin Chem 44:250-255

41. Schiekofer S, Balletshofer B, Andrassy M, Bierhaus A, Nawroth PP 2000 Endothelial dysfunction in diabetes mellitus. Semin Thromb Hemost 26:503-511

42. Pomilio M, Mohn A, Verrotti A, Chiarelli F 2002 Endothelial dysfunction in children with type 1 diabetes mellitus. J Pediatr Endocrinol Metab 15:343-361 